\title{
Self-Medication -An Intensifying Global Concern
}

\author{
Nida Tabassum Khan ${ }^{1 *}$, Hadia Habib ${ }^{1}$ \\ ${ }^{1}$ Department of Biotechnology, Faculty of Life Sciences \& Informatics, Balochistan University of Information Technology, Engineering and \\ Management Sciences, Takatu Campus, Airport Road, Quetta, Balochistan
}

*Corresponding Author: Nida Tabassum Khan, Department of Biotechnology, Faculty of Life Sciences \& Informatics, Balochistan University of Information Technology, Engineering and Management Sciences, Takatu Campus, Airport Road, Quetta, Balochistan

Received date: March 23, 2021; Accepted date: March 31, 2021; Published date: April 12, 2021

Citation: Nida Tabassum Khan, Hadia Habib (2021). Self-Medication -An Intensifying Global Concern. J Clinical Research and Reports,7(4); DOI: $10.31579 / 2690-1919 / 158$

Copyright: () 2021 Nida Tabassum Khan, This is an open access article distributed under the Creative Commons Attribution License, which permits unrestricted use, distribution, and reproduction in any medium, provided the original work is properly cited.

\begin{abstract}
As being one of the most available forms of health care, self-medication competes the need for valuable and sometimes important functions for the sole person and healthcare system. From the last two decades the practice of self-medication has been constantly increased. Self-medication has now become an important element of self-care and is practiced everywhere across the globe People are more prone to self-medication because they want immediate solution of every problem. Self-medication makes us rely on medicines without any proper prescription. It may offer some aid for a short period of time, but it always ends up with dangerous consequences.

Key words: consultation; chronic; prescription; self-analysis; pharmaceuticals; self-medication; self-diagnosed sickness; painkillers; antiallergics; cough syrups
\end{abstract}

\section{Introduction}

Due to the developments in the medical profession by scientific uncoverings of diagnostics, surgeries, and medicines, medical profession has transpired as a crucial profession in caring for human health [1]. However, the repercussion of this is that people became submissive in caring for themselves. Around 1960, self-care and self-medication was contemplated as unscientific. Thus, this became the reason for the overpricing of our health care system [2]. The increase in noncommunicable diseases can be avoided by self-care by responsible use of self-medication along with considering counter (OTC) drugs as a process of self-care and activities like hygiene, nutrition, and exercise become quotidian $[3,4]$. The patients are required to take all responsibilities for safe effective and safe self-medication [5].

Self-medication is defined as the usage of medicines without proper consultation from any healthcare experts or physicians [6]. In selfmedication individuals usually decide for themselves and start treating self-diagnosed sickness from acute to chronic without any prescription [7]. In other words, Self-medication can also be defined as using one or more medicines at a time, one's own home remedies and herbs without the consent from any doctor/experts to treat minor health problems [8]. Self-medicating does not always mean to treat minor problems like headache, flu, cough etc. but now-a-days people mostly self-medicate to treat depression, anxiety, any emotional or physical stress without any prescription [9].

Practice of self-medication has been increasing day by day in many countries. People usually take advice from friends, neighbors, pharmacists, and family members regarding self-medication or they use internet to find the suitable medicine that they think would help with their problem [10]. However, many self-therapeutic and diagnostic activities end up worsening their situation, but people still prefer independent and decision-making roles by themselves [11]. Self-medication is preferable for treating common sickness [12]. Studies shows that when people get sick, they turn to their friends, relatives, neighbor, instead of consulting a physician [13]. This raise worries of wrong self-analysis, drug cooperation, and utilize other than for the first sign [14]. Many experts believe that OTC drugs allow people to ignore grave symptoms until it is too late [15]. People mostly prefer self-medication when they are suffering from any psychiatric disorders, mental illness, anxiety, depression, allergy, diarrhea, menstrual pain, fever, constipation, fatigue, weakness cough and common cold $[16,17]$ to stabilize themselves or to stay normal by becoming their own doctor [18].

\section{Why Do People Use Self-Medication?}

Sometimes we feel down and worried while facing life's struggles, which makes us feel miserable and exhausted [19]. The feelings of hopelessness, anger, sadness, and fear start interfering our functions in daily life [20]. To overcome all these issues, instead of seeking medical help we prefer the simplest way possible, and that is self-medication [21]. We try to cope on our own which results in worsening the health. Besides, we all are under the dark thick clouds of coronavirus pandemic, instead of going to professional doctors we prefer to self-medicate. However, the things are still not back to normal, the threat of coronavirus still exists [22]. We, as a society are trying to find different ways to get rid of our depression and anxiety which is caused by coronavirus. Many people turn to drugs to cope with these issues, while others use alcohol to face situations to stay focused [23].

\section{Reasons for Self-Medication}

Self-medication is very typical and there are many reasons could be listed for it. For example: 
- Lack of time to visit a doctor.

- Insufficiency of health services

- Financial issue, unable to afford the doctors' fees.

- Previously prescribed medicines

- Misbelieves

- Easy availability of some OTC medicines in the stores, pharmacies, and markets.

- $\quad$ Need of self-care.

- Pharmaceuticals Advertisements

- Knowledge from books

- Internet

- Emergency conditions

- Demographic and epidemiological factors

- $\quad$ Lack of knowledge (Illiteracy)

- Social and environmental factors

- For minor symptoms people mostly prefer to treat them on their own without any consultation [24-27]

\section{Self-Medication and Addiction}

Self-medication does not only involve the use of medicines in low quantity, but it also involves usage of drugs practiced by many people across the globe [28]. While practicing self-medication, most people become dependent on those drugs or medicines that they have taking [29]. Medicines can be defined as those which are approved by doctors, but drugs are not approved especially for daily use. Drugs have the capacity to do good as well as cause suffering [30]. Addiction to drugs is always harmful in other words we can say addiction is a form of disease that slowly and steadily makes our life miserable. It affects both our behavior, brain, and our daily life [31]. When we are addicted to drug/medicines, we cannot hold out against the need to use them, despite knowing the dangerous consequences of drug addiction still we just cannot resist ourselves [32]. Self-medication has both its pros and cons if used appropriately, it will give you benefits but getting hooked to it is very dangerous. If used on day-to-day basis one can get easily addicted to alcohol, painkillers, nicotine, anti-anxiety medications, etc. [33]. Previous studies show for example, to cope with headache, we mostly prefer to take Paracetamol, and then we consider this particular medicine as the only option to get rid of headache, we get addicted to it and also stop consulting a doctor. Despite all of the benefits of medicines, their improper use will always lead towards adverse reactions, even death [34].

Individuals' decision of selecting a specific medication is not unintentional, it basically links with the person psychological condition [35]. Sometimes drugs that are harmful to the human body causes relief in psychological disorders [36]. At first, when individuals start using a specific drug, it will provide some sort of relief, and suddenly that individual feel very relaxed and comfortable then they start using this drug, to control their situation [37]. They decide on their own that how often they can use this drug or how much dosage they need without consultation [38]. But with the passage of time, it will end up with some unbearable consequences [39]. People who are constantly depressed due to troubled relationships, worry constantly, and have trouble in paying attention to anything, or if they want to get rid of any unpleasant memory that happened with them in their past, these kinds of persons are most likely to become addicted to drugs to feel better [40]. If we constantly use drugs for a long period of time, they badly affect our brain chemical system then it would become difficult for us to learn anything, to recall any memory as constant use of drugs greatly affects out memory, to make any judgement, to take any decision etc. [41].

\section{Incidence Rate}

The prevalence rate of self-medication is very high throughout the globe, but the low, and middle-income countries are more prone to self- medication [42]. The healthcare services are getting costlier and economically deprived countries have no access to healthcare services due to which practices of self-medication is getting increasing day by day [43]. In Pakistan, the prevalence rate of self-medication is around 51\% especially in rural areas due to lack of healthcare infrastructure [44]. Upto $70 \%$ population of Pakistan is lacking qualified doctors and medicines. People are unaware of dangerous consequences that arise from misuse of any non-prescribed medicine [45]. Another survey which was conducted in Agha khan university, Pakistan revealed that the prevalence rate of selfmedication is around $76 \%$, and the most commonly used medicines were antibiotics and antipyretics [46]. Prevalence rate of self-medication in Ethiopia was found to be around $36.8 \%$ [47]. A recent research study shows that prevalence rate of self-medication practice among medical, and pharmacy students in south India is around $86.54 \%$ and the major contributing factors were the previous experience of common sickness, and also from their knowledge from books [48]. Another survey conducted among university students in Iran shows that prevalence rate of self-medication with painkillers was around 76.6\% [49]. In Kuwait, the prevalence rate of self-medication practice among undergraduate medical students was very high almost around $98 \%$. The major factors for which people practice self-medication were headache, constipation, and menstrual pain [50]. Another study shows that prevalence rate of selfmedication was found to be $54 \%$ in turkey, $94 \%$ in Hong Kong and around $88 \%$ in Croatia. Commonly used drugs were painkillers, antiallergics and cough syrups [51]. In Nepal, the prevalence rate is found to be around $59 \%$, non-prescribed and herbal medicines were commonly used, and their misuse affects both the economy, country, and individuals [52].

\section{Conclusion}

Practice of self-medication is gaining worldwide recognition and people now prefer self-medication to manage their health problems at home or from sources like books, internet, signs of a condition that a family member or friend previously experienced, from advertisements, lack of accessibility of health personnel and many more, then treating them on their own without any proper consultation because it is easier and a time saving method.

\section{References}

1. Rutter, P. (2015). Role of community pharmacists in patients' self-care and self-medication. Integrated pharmacy research \& practice, $4,57$.

2. Bennadi, D. (2013). Self-medication: A current challenge. Journal of basic and clinical pharmacy, 5(1), 19.

3. Blenkinsopp, A., \& Bradley, C. (1996). Over the Counter Drugs: Patients, society, and the increase in self-medication. Bmj, 312(7031), 629-632.

4. Bradley, C., \& Blenkinsopp, A. (1996). Over the counter drugs: the future for self-medication. BMJ, 312(7034), 835-837.

5. Amoako, E. P., Richardson-Campbell, L., \& Kennedy-Malone, L. (2003). Self-medication with over-the-counter drugs among elderly adults. Journal of gerontological nursing, 29(8), 10-15.

6. Phalke, V. D., Phalke, D. B., \& Durgawale, P. M. (2006). Selfmedication practices in rural Maharashtra. Indian journal of community medicine, 31(1), 34.

7. Arrais, P. S. D., Fernandes, M. E. P., Pizzol, T. D. S. D., Ramos, L. R., Mengue, S. S., Luiza, V. L., ... \& Bertoldi, A. D. (2016). Prevalence of self-medication in Brazil and associated factors. Revista de saude publica, 50, $13 \mathrm{~s}$.

8. Figueiras, A., Caamano, F., \& Gestal-Otero, J. J. (2000). Sociodemographic factors related to self-medication in Spain. European journal of epidemiology, 16(1), 19-26.

9. Montastruc, J. L., Bagheri, H., Geraud, T., \& Lapeyre-Mestre, M. (1997). Pharmacovigilance of self-medication. Therapie, 52(2), 105-110. 
10. Chang, F. R., \& K. Trivedi, P. (2003). Economics of selfmedication: theory and evidence. Health economics, 12(9), 721739.

11. Deshpande, S. G., \& Tiwari, R. (1997). Self-medication--a growing concern. Indian journal of medical sciences, 51(3), 9396.

12. Chouhan, K. I. R. A. N. B. I. R., \& Prasad, S. B. (2016). Selfmedication and their consequences: a challenge to health professional. Asian J Pharm Clin Res, 9(2), 314-317.

13. Galato, D., Galafassi, L. D. M., Alano, G. M., \& Trauthman, S. C. (2009). Responsible self-medication: review of the process of pharmaceutical attendance. Brazilian Journal of Pharmaceutical Sciences, 45(4), 625-633.

14. Patel, P. M., Prajapati, A. K., Ganguly, B., \& Gajjar, B. (2013). Study on impact of pharmacology teaching on knowledge, attitude and practice on self-medication among medical students. Int $\mathbf{J}$ Med Sci Public Health, 2(2), 181-186.

15. James, H., Handu, S. S., Khaja, K. A., \& Sequeira, R. P. (2008). Influence of medical training on self-medication by students. International journal of clinical pharmacology and therapeutics, 46(1), 23-29.

16. Abay, S. M., \& Amelo, W. (2010). Assessment of Self-medication practices among medical, pharmacy, health science students in Gondar University, Ethiopia. Journal of Young Pharmacists, 2(3), 306-310.

17. Eticha, T., \& Mesfin, K. (2014). Self-medication practices in Mekelle, Ethiopia. PloS one, 9(5), e97464.

18. Hughes, C. M., McElnay, J. C., \& Fleming, G. F. (2001). Benefits and risks of self-medication. Drug safety, 24(14), 1027-1037.

19. Azami-Aghdash, S., Mohseni, M., Etemadi, M., Royani, S., Moosavi, A., \& Nakhaee, M. (2015). Prevalence and cause of selfmedication in Iran: a systematic review and meta-analysis article. Iranian journal of public health, 44(12), 1580.

20. Jalilian, F., Hazavehei, S. M. M., Vahidinia, A. A., Moghimbeigi, A., Zinat Motlagh, F., \& Mirzaei Alavijeh, M. (2013). Study of causes of self-medication among Hamadan Province Pharmacies Visitors. Avicenna Journal of Clinical Medicine, 20(2), 160-166.

21. Schmiedl, S., Rottenkolber, M., Hasford, J., Rottenkolber, D., Farker, K., Drewelow, B., ... \& Thürmann, P. (2014). Selfmedication with over-the-counter and prescribed drugs causing adverse-drug-reaction-related hospital admissions: results of a prospective, long-term multi-centre study. Drug safety, 37(4), 225-235.

22. Aziz, M. M., Masood, I., Yousaf, M., Saleem, H., Ye, D., \& Fang, Y. (2018). Pattern of medication selling and self-medication practices: A study from Punjab, Pakistan. PloS one, 13(3), $\mathrm{e} 0194240$

23. Khantzian, E. J., \& Albanese, M. J. (2008). Understanding addiction as self medication: Finding hope behind the pain. Rowman \& Littlefield Publishers.

24. Colder, C. R. (2001). Life stress, physiological and subjective indexes of negative emotionality, and coping reasons for drinking: Is there evidence for a self-medication model of alcohol use? Psychology of Addictive Behaviors, 15(3), 237.

25. Bakhtiar, K., Bastami, F., Sharafkhani, N., \& Almasian, M. (2017). The psychological determinants of self-medication among the elderly: an explanation based on the Health Belief Model. Elderly Health Journal, 3(2), 59-66.

26. Nepal, G., \& Bhatta, S. (2018). Self-medication with antibiotics in WHO Southeast Asian Region: a systematic review. Cureus, 10(4).

27. Grigoryan, L., Burgerhof, J. G., Degener, J. E., Deschepper, R., Lundborg, C. S., Monnet, D. L., ... \& Haaijer-Ruskamp, F. M. (2008). Determinants of self-medication with antibiotics in
Europe: the impact of beliefs, country wealth and the healthcare system. Journal of Antimicrobial Chemotherapy, 61(5), 11721179.

28. Khantzian, E. J. (2013). Addiction as a self-regulation disorder and the role of self-medication. Addiction, 108(4), 668-669.

29. Khantzian, E. J. (1997). The self-medication hypothesis of substance use disorders: A reconsideration and recent applications. Harvard review of psychiatry, 4(5), 231-244.

30. Weiss, R. D., Griffin, M. L., \& Mirin, S. M. (1992). Drug abuse as self-medication for depression: An empirical study. The American journal of drug and alcohol abuse, 18(2), 121-129.

31. Weiss, R. D., Griffin, M. L., \& Mirin, S. M. (1992). Drug abuse as self-medication for depression: An empirical study. The American journal of drug and alcohol abuse, 18(2), 121-129.

32. Suh, J. J., Ruffins, S., Robins, C. E., Albanese, M. J., \& Khantzian, E. J. (2008). Self-medication hypothesis: Connecting affective experience and drug choice. Psychoanalytic psychology, 25(3), 518.

33. Khantzian, E. J. (1990). Self-regulation and self-medication factors in alcoholism and the addictions. Similarities and differences. Recent developments in alcoholism: an official publication of the American Medical Society on Alcoholism, the Research Society on Alcoholism, and the National Council on Alcoholism, 8, 255-271.

34. Khantzian, E. J. (2003). The self-medication hypothesis revisited: The dually diagnosed patient. Primary Psychiatry, 10(9), 47-54.

35. Torres, C., \& Papini, M. R. (2016). Emotional self-medication and addiction. In Neuropathology of drug addictions and substance misuse (pp. 71-81). Academic Press.

36. Hall, D. H., \& Queener, J. E. (2007). Self-medication hypothesis of substance use: testing Khantzian's updated theory. Journal of Psychoactive Drugs, 39(2), 151-158.

37. Markou, A., Kosten, T. R., \& Koob, G. F. (1998). Neurobiological similarities in depression and drug dependence: a self-medication hypothesis. Neuropsychopharmacology, 18(3), 135-174.

38. Robinson, J., Sareen, J., Cox, B. J., \& Bolton, J. M. (2011). Role of self-medication in the development of comorbid anxiety and substance use disorders: a longitudinal investigation. Archives of General Psychiatry, 68(8), 800-807.

39. Shehnaz, S. I., Agarwal, A. K., \& Khan, N. (2014). A systematic review of self-medication practices among adolescents. Journal of adolescent health, 55(4), 467-483.

40. Loyola Filho, A. I. D., Lima-Costa, M. F., \& Uchôa, E. (2004). Bambuí Project: a qualitative approach to self-medication. Cadernos de saude publica, 20(6), 1661-1669.

41. Orriols, L., Gaillard, J., Lapeyre-Mestre, M., \& Roussin, A. (2009). Evaluation of abuse and dependence on drugs used for self-medication. Drug safety, 32(10), 859-873.

42. Osemene, K. P., \& Lamikanra, A. (2012). A study of the prevalence of self-medication practice among university students in Southwestern Nigeria. Tropical Journal of Pharmaceutical Research, 11(4), 683-689.

43. Paula Martins, A., da Costa Miranda, A., Mendes, Z., Soares, M. A., Ferreira, P., \& Nogueira, A. (2002). Self-medication in a Portuguese urban population: a prevalence study. Pharmacoepidemiology and drug safety, 11(5), 409-414.

44. Zafar, S. N., Syed, R., Waqar, S., Zubairi, A. J., Vaqar, T., Shaikh, M., ... \& Saleem, S. (2008). Self-medication amongst university students of Karachi: prevalence, knowledge and attitudes. Journal of the Pakistan Medical Association, 58(4), 214.

45. Aqeel, T., Shabbir, A., Basharat, H., Bukhari, M., Mobin, S., Shahid, H., \& Waqar, S. A. (2014). Prevalence of self-medication among urban and rural population of Islamabad, Pakistan. Tropical Journal of Pharmaceutical Research, 13(4), 627-633. 
46. Ullah, H. A. N. I. F., Khan, S. A., Ali, S., Karim, S., Baseer, A., Chohan, O., ... \& Murtaza, G. (2013). Evaluation of selfmedication amongst university students in Abbottabad, Pakistan; prevalence, attitude and causes. Acta Pol Pharm, 70(5), 919-922.

47. Ayalew, M. B. (2017). Self-medication practice in Ethiopia: a systematic review. Patient preference and adherence, 11, 401.

48. Kumar, V., Mangal, A., Yadav, G., Raut, D., \& Singh, S. (2015). Prevalence and pattern of self-medication practices in an urban area of Delhi, India. Medical Journal of Dr. DY Patil University, $8(1), 16$.

49. Jafari, F., Khatony, A., \& Rahmani, E. (2015). Prevalence of selfmedication among the elderly in Kermanshah-Iran. Global journal of health science, 7(2), 360 .
50. Abahussain, E., Matowe, L. K., \& Nicholls, P. J. (2005). Selfreported medication use among adolescents in Kuwait. Medical principles and practice, 14(3), 161-164.

51. Al Essa, M., Alshehri, A., Alzahrani, M., Bustami, R., Adnan, S., Alkeraidees, A., ... \& Gramish, J. (2019). Practices, awareness and attitudes toward self-medication of analgesics among health sciences students in Riyadh, Saudi Arabia. Saudi Pharmaceutical Journal, 27(2), 235-239.

52. Shankar, P. R., Partha, P., \& Shenoy, N. (2002). Self-medication and non-doctor prescription practices in Pokhara valley, Western Nepal: a questionnaire-based study. BMC family practice, 3(1), 17.
This work is licensed under Creative Commons Attribution 4.0 License

\section{To Submit Your Article Click Here: Submit Manuscript}

DOI: $10.31579 / 2690-1919 / 158$
Ready to submit your research? Choose Auctores and benefit from:

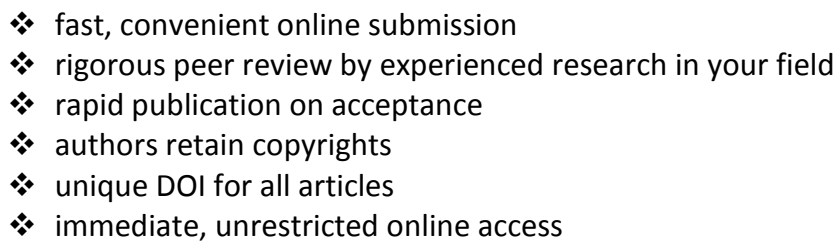

At Auctores, research is always in progress.

Learn more www.auctoresonline.org/journals/journal-of-clinicalresearch-and-reports 